\title{
A FAIXA DE DOBRAMENTOS PIANCÓ-ALTO BRÍGIDA: CONSTITUINTES, ESTRUTURA E RELAÇÕES ESTRUTURAIS COM OS CISALHAMENTOS DÚCTEIS DE PATOS E PERNAMBUCO
}

M.Egydio da Silva ${ }^{1}$

J.P.Lécorché ${ }^{2}$

R.Trompette ${ }^{2}$

\section{INTRODUÇÃO}

O Nordeste brasileiro ou Província Borborema é formado por um "mosaico" de blocos cratogênicos e faixas de dobramentos (BRITO NEVES, 1975 e 1983). Na borda sudeste, a faixa marginal de Sergipe limita o Cráton de São Francisco. A NNW do contato com o bloco cratônico de São Luís encontra-se parcialmente encoberto pelos sedimentos horizontais das bacias do Parnaíba e Costeira. A estruturação deste conjunto é de idade brasiliana (BRITO NEVES, 1983). Aproximadamente há 650 Ma., no Neoproterozóico, as coberturas sedimentares foram dobradas e metamorfizadas, o embasamento reativado e ocorreu o "emplacement" de corpos granitóides (SIAL et al., 1990).

Recentemente, no Seridó, SÁ (1987a, 1987b) limitou a influência da orogênese brasiliana a uma fase de dobras abertas e à intrusão de granitos. A fase mais importante da tectogênese seria transamazônica.

O grande traço estrutural é a presença de dois cisalhamentos dúcteis, Patos e Pernambuco, de centenas de quilômetros de extensão, limitando ao norte e ao sul a faixa de dobramentos Piancó-Alto Brígida. Em RIES \& HACKLETON (1977) estas grandes estruturas são consideradas de idade tardi-brasiliana.

${ }_{1}$ Departamento de Geologia Geral, Instituto de Geociências/USP, São Paulo.
${ }^{2}$ Universidade de Marseille, França. 
A idade dos metassedimentos não é conhecida. Muitas vezes é considerada do Proterozóico Superior por comparação com a idade do Supergrupo São Francisco. Na região de Orós (SÁ, 1987; MACEDO et al., 1988), as metavulcânicas foram datadas ao redor de 1700 e $1750 \mathrm{Ma}$. ( $\mathrm{Rb} / \mathrm{Sr}$ em rocha total), indicando a presença de materiais de idade do Proterozóico Médio. No Seridó (SÁ, 1987) os metassedimentos seriam de idade transamazônica. Na faixa de dobramentos Rio Preto (EGYDIO-DA-SILVA, 1987) os metassedimentos seriam constituídos pelos equivalentes dobrados e metamorfizados do Supergrupo São Francisco e do Grupo Chapada Diamantina (parte superior do Espinhaço). $\mathrm{Na}$ faixa Sergipana os metassedimentos seriam neoproterozóicos.

\section{A FAIXA PIANCÓ-ALTO BRÍGIDA}

Limitada pelos cisalhamentos dúcteis de Patos e Pernambuco, ela é constituída de metassedimentos metamorfizados na fácies xisto-verde superior a anfibolito alto.

Os Grupos Salgueiro e Cachoeirinha são interpretados como duas unidades litoestratigráficas superpostas ou como duas fácies metamórficas de uma mesma entidade litológica.

No atual estágio do trabalho é impossível afirmar se os metassedimentos brasilianos do NE do Brasil representam os restos de uma vasta superestrutura brasiliana ou, ao contrário, seriam originários da sedimentação em bacias neoproterozóicas independentes.

\section{1 - Considerações sobre a seção geológica Princesa Isabel - Santana dos Garrotes - Campina Grande}

O corte mostra uma sucessão de "blocos" separados por falhas rúpteis, controlando o contato dos metassedimentos, cujo grau de metamorfismo é muito diferente. As fácies mais metamórficas são geralmente mais abundantes nas extremidades norte e sul da faixa. Isto faz com que seja difícil a distinção embasamento reativado e metassedimento.

A distinção Salgueiro/Cachoeirinha se traduz à primeira vista em uma diferença de intensidade de metamorfismo. A fácies Cachoeirinha é a menos metamórfica. Para certos autores esta distinção se reforça com diferenças litológicas.

Na seção Princesa Isabel - Campina Grande é possível distinguir no conjunto Salgueiro-Cachoeirinha dois pacotes litoestratigráficos. O primeiro, muito espesso, com grande extensão, é constituido por xisto quartzítico com intercalações de metavulcânicas e 
mármores que correspondem ao Grupo Salgueiro e Grupo Cachoeirinha. O segundo, detrítico, corresponde a um depósito gravitacional composto de metaconglomerados passando a metaturbiditos, geralmente finos, associados às falhas sinsedimentares orientadas NE-SW a ENE-WSW, comparável à Fm. Seridó, no Rio Grande do Norte e Paraíba. Esta comparação sugere que ele pode se constituir na parte superior da coluna estratigráfica.

O Conjunto Superior foi depositado em grabens ou bacias limitadas for falhas sinssedimentares NE-SW e ENE-WSW. É impossível reconstituir a geometria da bacia na qual estes sedimentos e o conjunto xisto-quartzítico foi depositado.

As grandes transcorrências E-W do tipo Patos-Pernambuco são posteriores a estas falhas sinssedimentares. Não se distingue uma vergência clara nos trabalhos de reconhecimento. É possível que, como na faixa Rio Preto, ocorra uma estrutura em flor associada à cinemática da transcorrência dúctil.

\section{2 - Consideraçổes sobre a seção geológica Salgueiro-Serrita - Sítio dos Moreiras}

A seção geológica mostra os metassedimentos dos Grupos Salgueiro e Cachoeirinha, seu embasamento e granitoides intrusivos.

A distinção entre os metassedimentos do Grupo Salgueiro e Cachoeirinha baseia-se na diferença marcante entre os seus graus metamórficos.

O Grupo Salgueiro apresenta grau metamórfico mais alto e, na porção oeste da seção, torna-se difícil a distinção desta unidade com o seu embasamento. Por outro lado, o Grupo Cachoeirinha caracteriza-se por uma fácies de metamorfismo baixo, do tipo xisto-verde, com a presença de filitos, sericita-xistos, clorita-xistos, metarenitos micáceos e possivelmente metaturbiditos (região de Verdejante).

Ao longo da seção geológica não se observa uma passagem gradual entre as duas unidades. Elas estão dispostas lado a lado, possivelmente em decorrência de um tectonismo rúptil com falhas transcorrentes, inversas e de empurrão.

A litologia característica do Grupo Salgueiro compreende biotita-quartzo xisto, biotita-moscovita-quartzo xisto, granada-biotita-quartzo xisto, sillimanita-moscovita xisto e xisto feldspático.

A xistosidade principal possui um "trend" regional NE-SW com mergulhos preferencialmente para o quadrante SE, com nítida vergência tectônica para NW. Fases posteriores de deformações mostram vergência para SE. Considerações conclusivas sobre a história deformacional da região são prematuras.

A análise cinemática dos grandes lineamentos transcorrentes que cortam a 
região têm revelado um deslocamento destral para o lineamento de Pernambuco.

\section{CONCLUSÕES}

1) Existência provável de dois pacotes litológicos distintos para a faixa Piancó-Alto Brígida. Os metaconglomerados a turbiditos podem ser os equivalentes da Formação Serido. Na faixa homônima nos estados da Paraíba e Rio Grande do Norte, eles podem ser correlacionados com as fácies do Bebedouro (Proterozóico Superior) do cráton do São Francisco.

2) As grandes transcorrências dúcteis EW são posteriores às falhas sinsedimentares NE-SW observadas. Os grandes lineamentos EW possuem um deslocamento destral em sua deformação principal.

3) A ausência de vergência nítida poderia resultar de uma estrutura em flor associada ao cisalhamento.

\section{REFERÊNCIAS BIBLIOGRÁFICAS}

ARCHANJO, C.J. \& SALIM, J. (1986) Posição da formação Serido, no contexto estratigráfico regional (RN - PB). In: SIMPÓSIO DE GEOLOGIA DO NORDESTE, 12., João Pessoa, 1986. Atas. João Pessoa, SBG/DNPM/CPRM. p.270-281 (Boletim n² 10).

BRITO NEVES, B.B. de (1975) Regionalização geotectônica do Precambriano nordestino. São Paulo, 198p. (Tese de Doutoramento, Instituto de Geociências/USP).

BRITO NEVES, B.B. de (1983) O mapa geológico do Nordeste Oriental do Brasil, escala 1/1.000.000. São Paulo, 177p. (Tese de Livre-Docência, Instituto de Geociências/USP).

EBERT, H. (1970) The Precambrian geology of the "Borborema" Belt (States of Paraiba and Rio Grande do Norte; northeastern Brazil) and the origin of its mineral provinces. Geologische Rundschau, 59:1292-1326.

EGYDIO-DA-SILVA, M.E. (1987) O sistema de dobramentos Rio Preto e suas relações com 
o cráton do São Francisco. São Paulo, 141p. (Tese de Doutoramento, Instituto de Geociências/USP).

MACEDO, M.H.F.; SÁ, J.M.; KAWASHITA, K. (1988) A idade da Faixa Orós: dados preliminares. Revista Brasileira de Geociências, 18(3):362-368.

RIES, A.C. \& SACKLETON, R.M. (1977) Preliminary note on structural sequences and magnetude suit orientation of finite strains in the Precambrian of Northeast Brazil. In: SIMPÓSIO DE GEOLÓGIA DO NORDESTE, 8., Campina Grande, 1977. Atas. Campina Grande, SBG. p.397-400. (Boletim n²6)

SÁ, E.F.J. de (1987a) Evolução orogênica monocíclica vs policíclica: (I) Argumentos estratigraficos e geocronológicos no Proterozóico da Província Borborema. In: SIMPÓSIO NACIONAL DE ESTUDOS TECTÔNICOS, 1., Salvador, 1987. Boletim de Resumos. Salvador, Curso de Pós-Graduação em Geologia da UFBA. p.9-11.

SÁ, E.F.J. de (1987b) Evolução orogênica monocíclica vs policíclica: (II) Argumentos estruturais no Proterozóico da Província de Borborema. In: SIMPÓSIO NACIONAL DE ESTUDOS TECTÔNICOS, 1., Salvador, 1987. Boletim de Resumos, Salvador, Curso de Pós-Graduação em Geologia da UFBA. p.12-14.

SIAL, A.N.; SASAKI, A.; FERREIRA, V.P. (1990) Oxygen and sulfur isotope geochemistry of brasiliano age granitoids in Northeast Brazil. The Bulletin of the Faculty of Education, (39):31-46. 